\title{
Residential green space and pathways to term birth weight in the Canadian Healthy Infant Longitudinal Development (CHILD) Study
}

Leanne Cusack ${ }^{1 \dagger}$, Hind Sbihi ${ }^{2,11 \dagger}$, Andrew Larkin ${ }^{1}$, Angela Chow ${ }^{3}$, Jeffrey R. Brook ${ }^{4}$, Theo Moraes ${ }^{5}$, Piush J. Mandhane ${ }^{6}$, Allan B. Becker ${ }^{7}$, Meghan B. Azad ${ }^{7}$, Padmaja Subbarao ${ }^{8}$, Anita Kozyrskyj ${ }^{6}$, Tim K. Takaro ${ }^{9}$, Malcolm R. Sears ${ }^{10}$, Stuart E. Turvey ${ }^{2,11}$, Perry Hystad ${ }^{12^{*}}$ (D) and the CHILD Study Investigators

\begin{abstract}
Background: A growing number of studies observe associations between the amount of green space around a mother's home and positive birth outcomes; however, the robustness of this association and potential pathways of action remain unclear.

Objectives: To examine associations between mother's residential green space and term birth weight within the Canadian Healthy Infant Longitudinal Development (CHILD) study and examine specific hypothesized pathways.

Methods: We examined 2510 births located in Vancouver, Edmonton, Winnipeg, and Toronto Canada. Green space was estimated around mother's residences during pregnancy using Landsat $30 \mathrm{~m}$ normalized difference vegetation index (NDVI). We examined hypothesized pathways of: (1) reduction of environmental exposure; (2) built environment features promoting physical activity; (3) psychosocial conditions; and (4) psychological influences. Linear regression was used to assess associations between green space and term birth weight adjusting first for a comprehensive set of confounding factors and then incrementally for pathway variables.

Results: Fully adjusted models showed non-statistically significant increases in term birth weight with increasing green space. For example, a 0.1 increase in NDVI within $500 \mathrm{~m}$ was associated with a $21.5 \mathrm{~g}(95 \% \mathrm{Cl}-4.6,47.7)$ increase in term birth weight. Associations varied by city and were most robust for high-density locations. For the two largest cities (Vancouver and Toronto), we observed an increase in birth weight of $41.2 \mathrm{~g}(95 \% \mathrm{Cl} 7.8,74.6)$ for a 0.1 increase in NDVI within $500 \mathrm{~m}$. We did not observe substantial reductions in the green space effect on birth weight when adjusting for pathway variables.
\end{abstract}

Conclusion: Our results highlight the need to further characterize the interactions between green space, urban density and climate related factors as well as the pathways linking residential green space to birth outcomes.

Keywords: Green space, Nature, Built environment, Birth weight, Birth outcomes

\footnotetext{
*Correspondence: perry.hystad@oregonstate.edu

${ }^{\dagger}$ Leanne Cusack and Hind Sbihi have contribute equally to this work

${ }^{12}$ College of Public Health and Human Sciences, Oregon State University, 2520 SW Campus Way, Corvallis, OR 97331, USA

Full list of author information is available at the end of the article

CHILD Study Investigators are listed in the acknowledgements
} 


\section{Introduction}

Proximity to green spaces has been linked to positive health outcomes. An increased amount of green space around a woman's home during pregnancy has been associated with a reduced risk of delivering a baby that is small for gestational age [1], lower rates of pre-term birth [2] and higher birth weight at term [3-6]. Importantly, the pathways through which green space may influence these birth outcomes remain unclear [7]. A number of different pathways have been hypothesized, including: (1) the reduction of harmful environmental exposures, including air pollution and noise; (2) providing space for increased utilitarian and recreational physical activity; (3) providing a setting for positive psychosocial influences; and (4) through directly reducing psychological stress and depression [8].

Most green space and birth outcome studies have not been able to comprehensively examine these hypothesized pathways. For example, a study by our group in Vancouver, Canada was able to examine air pollution, walkability and proximity to parks and found that the addition of these variables did not affect the associations between green space and birth weight [6]. In a large Southern California study [2], different air pollutants had considerable impact on the association between green space and birth weight but a study of four Spanish birth cohorts observed only moderate reductions in the green space birth weight association with the inclusion of $\mathrm{NO}_{2}$ air pollution [5]. While studies of green space and other health outcomes have started to examine mediation by different pathways $[9,10]$, direct evidence for the pathways linking green space exposure during pregnancy to birth outcomes does not exist.

Indirect evidence remains important as it provides support for the potential pathways of influence linking green space to birth outcomes. For instance, motor vehicle transportation not only produces air pollutants and noise, but also changes urban form (e.g., walkability) and access to natural environment and green spaces. Thus, while high levels of exposure to ambient air pollution during pregnancy have been shown to be associated with low birth weight [11-14], vegetated areas have less emission sources and may also improve air quality by filtering $\mathrm{NO}_{2}$ and particulate matter $\left(\mathrm{PM}_{10}\right)$ [15]. A growing body of research also demonstrates that physical activity during pregnancy can reduce the risk of having a low birth weight baby [16-19] and there is evidence of a positive association between green space access and increased physical activity [20-22]. More recently, measures such as walkability, also associated with residential green space in certain areas, have been linked to higher levels of physical activity [6, 23]. Parks and green spaces can also facilitate social cohesion by providing a meeting place for people to develop and maintain social interactions [24-26], which have also been linked to improved birth outcomes $[27,28]$. In a recent study, green space was associated with decreased depressive symptoms in pregnant women [10], and women with depression during pregnancy are at increased risk for adverse birth outcomes [29]. These intertwined exposures and pathways demonstrate the need to examine the specific pathways that potentially link urban green space to term birth weight.

We leveraged the Canadian Healthy Infant Longitudinal Development (CHILD) study (www.childstudy.ca), to examine associations between mother's residential green space during pregnancy and term birth weight across four Canadian urban areas (Vancouver, Edmonton, Winnipeg, and Toronto). Given the detailed information collected in CHILD we were able to adjust for multiple potential confounding factors and evaluate a comprehensive set of hypothesized pathways. This study provides the first opportunity to broadly examine how urban green space may influence term birth weight.

\section{Methods \\ CHILD birth cohort}

The CHILD Study recruited 3623 pregnant women from the general population across 4 Canadian urban metropolitan areas (Vancouver, British Columbia; Edmonton, Alberta; Winnipeg, Manitoba; and Toronto, Ontario) from 2009 to 2012. After excluding 83 children who were ineligible at birth and 45 families who failed to begin the study, we further restricted our analyses to mothers living in metropolitan areas and with complete residential history and covariate data. Our final sample size included 2510 births. Detailed data collection methods and characteristics of the CHILD Study have been previously described [30, 31]. Briefly, pregnant women aged 18 years or older (19 years or older in Vancouver) and infants born after 34 weeks gestation with no congenital abnormalities were eligible. Due to the gestational length restriction we only examine term birth weight ( $\geq 37$ weeks gestation). Questionnaires collected information on environmental exposures, psychosocial factors, and general health at several time points: recruitment (mean 27 weeks gestation), 36 weeks gestation and birth. Ethics approval for each CHILD center was obtained from local authorized review boards as well as McMaster University and Oregon State University.

\section{Assessment of residential green space}

We measured green space exposure using the average of Landsat $530 \mathrm{~m}$ normalized difference vegetation index (NDVI) around mothers' residential addresses during the 9 months of pregnancy. A time-weighted average from 
all addresses during pregnancy (11.5\% of participants moved) was computed for different buffer distances (i.e., $100 \mathrm{~m}, 250 \mathrm{~m}, 500 \mathrm{~m}, 1000 \mathrm{~m}$ ) around addresses since there is no consensus as to what buffer radius is most representative of green space exposures [8]. NDVI is an indicator of overall greenness based on land surface reflectance of the visible and near infrared parts of spectrum [33], with values ranging from -1 to 1 with the higher numbers indicating more greenness.

\section{Assessment of the four pathways hypothesized to link green spaces to birth outcomes}

We examined four general pathways that are hypothesized to link green space to birth outcomes. These include: (1) the reduction of harmful environmental exposures, particularly air pollution and noise; (2) providing space for increased utilitarian and recreational physical activity; (3) providing a setting for positive psychosocial influences; and (4) through directly reducing psychological stress and depression [8].

\section{Air pollution}

We included Nitrogen Dioxide $\left(\mathrm{NO}_{2}\right)$, fine particulate matter $\left(\mathrm{PM}_{2.5}\right)$, and Ozone $\left(\mathrm{O}_{3}\right)$ air pollution in our analyses. $\mathrm{NO}_{2}$ is of primary interest since this pollutant demonstrates fine-scale spatial variability that is most likely influenced by residential green space levels [32]. We applied a previously developed national land use regression (LUR) model for $\mathrm{NO}_{2}$, which includes satellite $\mathrm{NO}_{2}$ estimates and land use variables [33]. The final LUR model, which was further spatially calibrated based on a distance-decay gradient in $\mathrm{NO}_{2}$ around major roadways, explained $73 \%$ of the variation in annual 2006 national air quality monitoring network measurements of $\mathrm{NO}_{2}$. We adjusted these estimates based on ground-level annual average measurements of $\mathrm{NO}_{2}$ to match pregnancy years. $\mathrm{PM}_{2.5}$ air pollution was assessed using 2010-2013 satellite data at an approximate resolution of $1 \times 1 \mathrm{~km}$ fused with a chemical transport model and available ground level $\mathrm{PM}_{2.5}$ monitoring data [34]. Ozone air pollution was assessed using the 2002-2009 Canadian and Hemispheric Regional Ozone and $\mathrm{NO}_{\mathrm{x}}$ System (CHRONOS) operational regional air quality forecast model at an approximate $21 \times 21 \mathrm{~km}$ resolution [35].

\section{Noise}

Noise models were available only for Vancouver and Toronto and were therefore only included in sensitivity analyses. In Vancouver, the Computer Aided Noise Abatement (CadnaA) propagation model was used to derive residential noise estimates. Inputs to the model included traffic data (e.g., speed limits, traffic volume, fleet composition, and road width), railway data (e.g., type of train, velocity, and frequency), aircraft data and building heights and footprints. The creation and evaluation of this model has been described previously [36]. In Toronto, a LUR model was used to predict noise from 554 short-term (30 $\mathrm{min}$ ) and 10 long-term (1 week long) measurements [37]. The Toronto noise LUR model explained $74 \%$ and $68 \%$ of the spatial variability in the hot and cold season, respectively.

\section{Opportunity for physical activity}

Park proximity and neighborhood walkability may link green space, mother's physical activity and birth outcomes. We used a dichotomous variable for distance to park (residing less than or more than $400 \mathrm{~m}$ ) since residents living closer to a park are more likely to use the park for physical activity $[38,39]$. WalkScore ${ }^{\circledR}$ was used to represent neighborhood walkability. The walkability measure is a proprietary measure that is based on the distance to nearby places, block length and pedestrian friendliness, ranging from 0 to 100 , with higher values reflecting high walkable neighborhoods in which daily errands would not require a vehicle (WalkScore 2017).

\section{Perceived social support}

Social support was measured using the validated 4-item Interpersonal Support Evaluation List-12 (ISEL-12), a measure of perceived social support [40]. This survey was administered at 36 weeks of gestation. Example questions included: I feel that there is no one I can share my most private worries and fears with; if I were sick, I could easily find someone to help me with my daily chores (options (1) definitely false, (2) probably false, (3) probably true, (4) definitely true). An overall social support score was generated by summing the responses of all 12 items, with values ranging from 22 to 44 (higher score indicates higher perceived social support). This variable was included as a continuous variable in regression models, with tertiles examined in stratified analysis.

\section{Psychological stress and depression}

Participants answered questions about self-reported experienced stress using the Perceived Stress Scale (PSS) [41], which is a validated 10-item scale measuring the degree to which situations in one's life are appraised as stressful. The values ranged from 0 to 40 with a higher score indicating more stress [41]. Similar to social support, perceived stress was reported around 36 weeks of pregnancy and was included as a continuous variable, with tertiles examined in stratified analysis.

Participants also answered questions regarding depression using the 20 item Center for Epidemiologic Studies Depression Scale Revised (CESD-R) [42]. The range of possible scores is between 0 and 60 with a higher number 
indicating more symptoms of depression. We used the 36 week CESD-R questionnaire to align with the other psychosocial measures. The depression measure was examined as a continuous variable and tertiles examined in stratified analysis.

\section{Covariates}

A comprehensive set of covariates were available at the individual and neighborhood level to control for potential confounding factors. Individual socio-demographic covariates collected from the study questionnaires include: maternal age; mother and father's education (coded as less than high school diploma, high school diploma, some college, college degree and post graduate degree); mother and father's race (White, Asian, and Other); and household income (\$0-\$9999, $\$ 10,000-\$ 19,999, \quad \$ 20,000-\$ 29,999$. \$30,000-\$39,999, $\$ 40,000-\$ 49,999, \quad \$ 50,000-\$ 59,999, \quad \$ 60,000-\$ 79,999$. $\$ 80,000-\$ 99,999, \$ 100,000-\$ 149,999,>\$ 150,000)$. Pregnancy data included parity (first birth or not); smoking during pregnancy (yes/no); and month and year of birth. An indoor air quality index was also included that estimates the total exposure to multiple oxidizing chemicals in the home, which provides a more complete assessment of multiple indoor exposures linked to inflammation [43].

Neighborhood SES variables and population density $\left(\right.$ per $\mathrm{km}^{2}$ ) were also included at the census tract level for the 2011 census and linked to each birth. Variables included percent white; percent adult population without a high school diploma; median household income; percentage of the population below the poverty line; and percent unemployment. Population density (coded into quintiles) was used to control for potential confounding factors associated with urban form, such as inner city cores or suburban areas. We also derived a proximity to water (e.g., river, lake, ocean) variable (residing less than or more than $500 \mathrm{~m}$ ) to control for blue-space related influences that have been identified in other research [44].

\section{Statistical analysis}

We evaluated the associations between mother's residential green space exposure during pregnancy and term birth weight, and examined the following pathways: environmental exposures $\left(\mathrm{NO}_{2}, \mathrm{PM}_{2.5}\right.$ and $\left.\mathrm{O}_{3}\right)$, physical activity (Walkscore ${ }^{\circledR}$, park and water proximity), psychosocial influences (social support), and psychological influences (maternal stress and depression).

First, we examined the overall association between green space and birth weight. Linear regression, with a random intercept to account for the clustering within each study city, was used to assess associations between residential NDVI and term birth weight (babies born $\geq 37$ weeks of gestation) adjusting for a comprehensive set of individual and neighborhood confounding factors. The fully adjusted model includes all individual and neighborhood variables summarized previously. Associations between NDVI and birth weight are presented corresponding to a 0.1 unit increase in NDVI. We also ran overall models stratified by individual and contextual level variables selected a priori to examine potential effect modification and evaluate residual confounding.

Next, we examined hypothesized pathways using incremental analyses. We used linear regression to examine the associations between green space and $\mathrm{NO}_{2}, \mathrm{PM}_{2.5}$, $\mathrm{O}_{3}$, Walkscore ${ }^{\circledR}$, park and water proximity, social support and maternal stress and depression. Incremental models were then run that included each hypothesized pathway variable(s) separately and then all pathways together. Each model was adjusted for potential confounding factors included in the overall adjusted model.

Several sensitivity analyses were conducted to examine the robustness of our models. We explored city-specific models as cities had large differences in terms of size/ density, climate, and green space characteristics. Vancouver and Toronto also had available noise models and sensitivity analyses were conducted to examine how the NDVI and birth weight associations changed in these cities once noise exposures were included. We also evaluated the sensitivity of our results to including a random effects for neighborhoods, represented by Census Tract boundaries. And lastly, we examined the associations between season and birth weight by combining several months into a season variable (June-August, September-November, December-February, March-May).

\section{Results}

After exclusions for missing residential addresses and covariate information and restricting to urban metropoli$\tan$ areas we examined 2510 births in the CHILD study. Figure 1 illustrates the general location of CHILD participants (locations randomly assigned to Census Tracts) by the four CHILD cities, with average NDVI levels for the year 2010.

Table 1 provides selected descriptive statistics for the 2510 births included in our analysis by quartiles of average NDVI within $500 \mathrm{~m}$ during pregnancy. The mean NDVI (500 $\mathrm{m}$ buffer) during pregnancy was 0.26 with a range of $0.05-0.61$. Term birth weight was higher $(3491 \mathrm{~g})$ in quartile 4 (reflecting higher NDVI) compared to quartile 1 (3458 g). Differences in key socio-demographic characteristics by NDVI quartile were observed for race/ethnicity, education and income. Overall, the CHILD study is well educated (93.2\% of mothers had at least some college education) and predominantly white (70.8\%). Population density, 


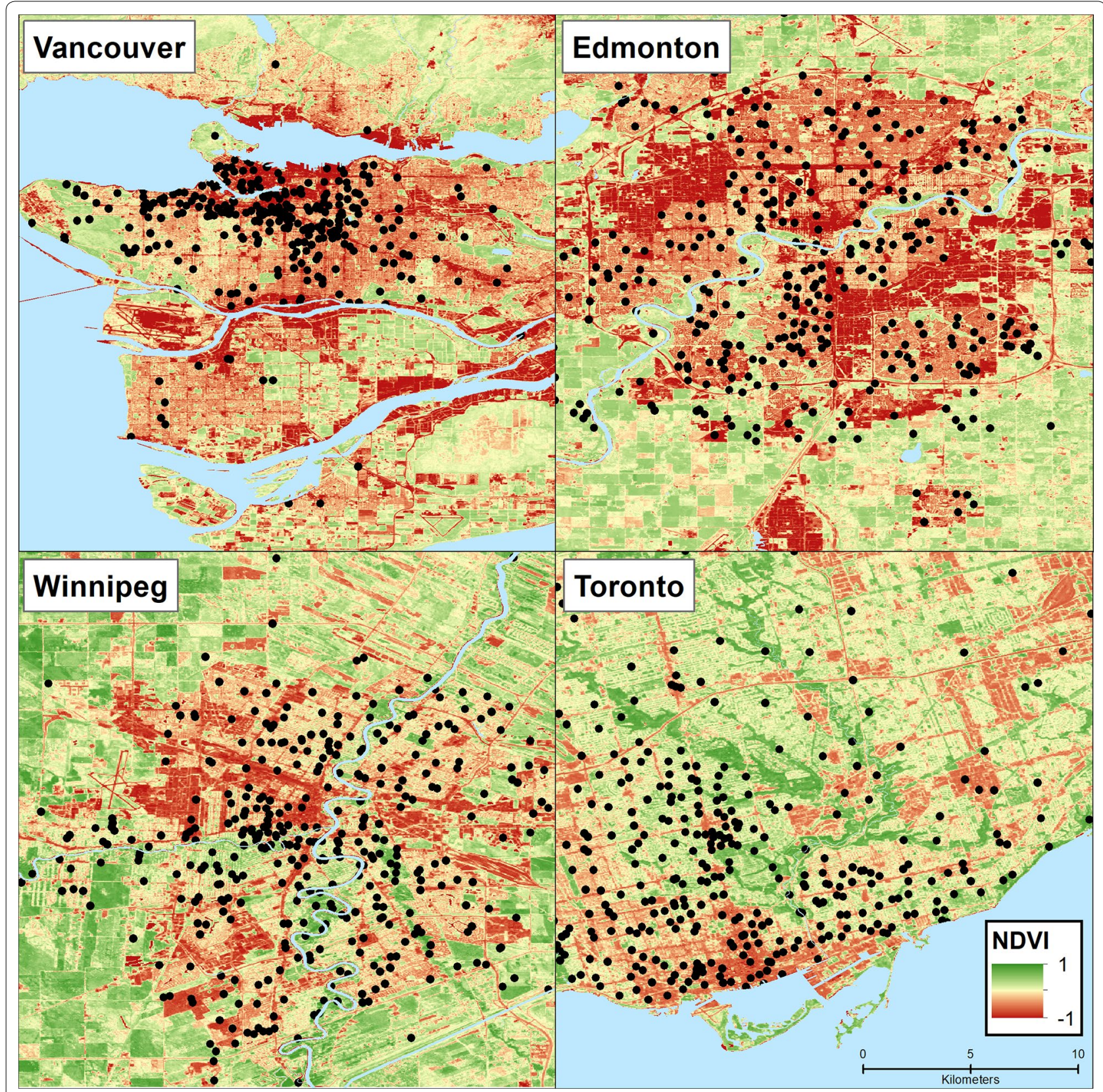

Fig. 1 Map of CHILD participants (points randomly assigned within study Census tracts) in the four Canadian cities, with average NDVI levels for the year 2010

$\mathrm{NO}_{2}$ and stress are lower in the highest green space quartile compared to the least green quartile, and the WalkScore ${ }^{\circledR}$ measure is higher in the least green areas.

\section{Associations between green space and term birth weight}

Table 2 summarizes model results for changes in term birth weight associated with a 0.1 increase in residential NDVI during pregnancy. We observed increased birth weight with increasing NDVI for buffer distances greater than $100 \mathrm{~m}$, with the largest associations for NDVI within $500 \mathrm{~m}$. Adjustment for individual and neighborhood covariates led to an attenuation of the association for NDVI within $100 \mathrm{~m}$, but increased associations for NDVI in 500 and $1000 \mathrm{~m}$.

Figure 2 summarizes stratified models of green space and term birth weight. We summarize only NDVI within $500 \mathrm{~m}$ as this is the distance in which we observed the largest and most consistent associations with term 
Table 1 Selected characteristics of 2510 births in the CHILD study by quartile of average NDVI within $\mathbf{5 0 0} \mathrm{m}$ of mothers residences during pregnancy

\begin{tabular}{|c|c|c|c|c|c|}
\hline & Entire cohort & Average NDVI & Buffer) & & \\
\hline & & $\begin{array}{l}\text { Q1 } \\
<0.21\end{array}$ & $\begin{array}{l}\mathrm{Q} 2 \\
0.21-0.25\end{array}$ & $\begin{array}{l}\mathrm{Q3} \\
0.26-0.30\end{array}$ & $\begin{array}{l}\mathrm{Q4} \\
>0.30\end{array}$ \\
\hline Births (n) & 2510 & 627 & 628 & 631 & 624 \\
\hline Birth weight $(g)(\bar{x}, s d)$ & $3474(498)$ & $3458(522)$ & $3471(481)$ & $3475(476)$ & $3491(513)$ \\
\hline Maternal age $(\bar{x}, s d)$ & $32.1(4.6)$ & $32.1(4.5)$ & $32.0(4.5)$ & $32.0(4.8)$ & $32.5(4.4)$ \\
\hline Maternal education (\%) & & & & & \\
\hline High school diploma & 6.8 & 6.8 & 7.6 & 8.1 & 4.9 \\
\hline Some college & 27.5 & 26.2 & 27.4 & 27.5 & 28.8 \\
\hline College degree & 45.0 & 44.8 & 46.5 & 42.9 & 45.8 \\
\hline Post Graduate degree & 20.6 & 22.1 & 18.5 & 21.5 & 20.5 \\
\hline Household income (\%) & & & & & \\
\hline$<\$ 30,000$ & 2.8 & 4.1 & 2.1 & 2.4 & 2.9 \\
\hline$\$ 30,000-\$ 49,999$ & 4.9 & 4.4 & 5.5 & 5.6 & 3.6 \\
\hline$\$ 50,000-\$ 79,000$ & 21.3 & 19.7 & 21.5 & 25.5 & 18.7 \\
\hline$>\$ 80,000$ & 71.0 & 71.8 & 70.9 & 66.5 & 74.7 \\
\hline Maternal ethnicity (\%) & & & & & \\
\hline White & 70.8 & 68.8 & 70.1 & 71.9 & 72.4 \\
\hline Asian & 10.7 & 11.0 & 12.0 & 9.1 & 10.5 \\
\hline Other & 18.5 & 20.2 & 17.9 & 19.0 & 17.1 \\
\hline Smoked during pregnancy (\%) & 3.3 & 2.9 & 3.8 & 3.4 & 2.9 \\
\hline Moved during pregnancy (\%) & 11.5 & 15.2 & 10.8 & 8.5 & 11.8 \\
\hline Social support $(\bar{x}, s d)$ & $31.3(2.2)$ & $31.2(2.3)$ & $31.4(2.2)$ & $31.3(2.2)$ & $31.0(2.0)$ \\
\hline Depression $(\bar{x}, s d)$ & $9.5(7.4)$ & $9.7(7.8)$ & $9.6(7.8)$ & $9.6(7.6)$ & $9.2(6.6)$ \\
\hline Stress $(\bar{x}, s d)$ & $12.5(6.3)$ & $12.8(6.4)$ & $11.9(6.3)$ & $12.6(6.2)$ & $12.6(6.2)$ \\
\hline Walk score $(\bar{x}, s d)$ & $60.0(27.7)$ & $70.0(28.7)$ & $61.0(27.6)$ & $58.4(24.7)$ & $49.8(25.5)$ \\
\hline $\mathrm{NO}_{2}$ air pollution (ppb) $(\bar{x}, s d)$ & $18.3(5.1)$ & $20.3(5.3)$ & $18.4(4.5)$ & $18.0(4.6)$ & $16.5(5.1)$ \\
\hline $\mathrm{PM}_{2.5}$ air pollution $(\mathrm{ppb})(\bar{x}, s d)$ & $6.9(1.5)$ & $7.0(1.4)$ & $7.0(1.3)$ & $7.1(1.4)$ & $6.7(1.6)$ \\
\hline $\mathrm{O}_{3}$ air pollution $(\mathrm{ppb})(\bar{x}, s d)$ & $25.1(4.5)$ & $25.0(4.5)$ & $25.0(4.3)$ & $25.3(3.9)$ & $25.7(4.0)$ \\
\hline Population $/ \mathrm{km}^{2}(\bar{x}, \mathrm{sd})$ & $4370(3406)$ & $5789(4580)$ & $4614(3230)$ & $3775(2396)$ & $3280(2413)$ \\
\hline $\begin{array}{l}\text { Neighborhood median household } \\
\text { income }(\bar{x}, s d)\end{array}$ & $70,498(29,597)$ & $65,346(26,899)$ & $68,812(26,867)$ & $72,059(27,060)$ & $76,007(35,887)$ \\
\hline Neighborhood \% minority $(\bar{x}, s d)$ & $33.2(23.0)$ & $36.1(21.1)$ & $34.2(22.7)$ & $32.8(24.0)$ & $29.5(23.7)$ \\
\hline City (\%) & & & & & \\
\hline Vancouver & 24.7 & 28.2 & 25.1 & 20.2 & 21.9 \\
\hline Edmonton & 25.0 & 21.1 & 26.5 & 31.6 & 21.3 \\
\hline Winnipeg & 23.4 & 23.2 & 24.0 & 22.7 & 24.9 \\
\hline Toronto & 26.9 & 27.4 & 24.5 & 25.6 & 31.9 \\
\hline
\end{tabular}

weight. We see patterns of larger associations between NDVI and birth weight for higher SES mothers (higher educated, white and higher income neighborhoods) and mothers living in higher population density neighborhoods (represented by population density as well as higher $\mathrm{NO}_{2}$ and $\mathrm{PM}_{2.5}$ exposures and neighborhood walkability scores). Mothers with low perceived social support also had larger associations. Models stratified by CHILD cities demonstrated heterogeneous results, with large positive associations between NDVI and birthweight for Toronto and Vancouver and a negative association for Edmonton.

\section{Potential pathways linking green space and term birth weight}

Incremental models of hypothesized pathway variables are summarized in Table 3. Data from the remaining buffer sizes demonstrated similar results to the NDVI $500 \mathrm{~m}$ exposure variable. These models are presented in general pathways (reducing environmental exposures; 


\begin{tabular}{|c|c|c|c|}
\hline NDVI Buffer & $\begin{array}{l}\text { Model } 1 \\
\beta(95 \% \mathrm{Cl})\end{array}$ & $\begin{array}{l}\text { Model } 2 \\
\beta(95 \% \mathrm{Cl})\end{array}$ & $\begin{array}{l}\text { Model } 3 \\
\beta(95 \% \mathrm{Cl})\end{array}$ \\
\hline $100 \mathrm{~m}$ & $14.1(-5.4,33.7)$ & $3.9(-17.4,25.2)$ & $4.0(-18.1,26.1)$ \\
\hline $250 \mathrm{~m}$ & $16.5(-4.6,37.6)$ & $11.6(-11.4,34.6)$ & $12.7(-11.6,36.9)$ \\
\hline $500 \mathrm{~m}$ & $18.8(-3.4,41.1)$ & $18.3(-6.1,42.7)$ & $21.5(-4.6,47.7)$ \\
\hline $1000 \mathrm{~m}$ & $15.7(-7.2,38.7)$ & $14.4(-10.8,39.5)$ & $17.8(-9.5,45.0)$ \\
\hline
\end{tabular}

Model 1: Unadjusted model includes gestational age

Model 2: Model 1 plus individual characteristics: baby's sex, year and month of birth, mother's age, mothers smoking during pregnancy, mother/father education, mother/father race/ethnicity, household income, indoor air quality index and city

Model 3: Model 2 plus neighborhood household income, \% without high school education, unemployment, \% minority and population density at $1 \mathrm{~km}$

physical activity opportunities; psychosocial influences; psychological influences) with individual variables entered independently in models as well as all variables by pathway. As shown in Table 3, an increase in NDVI is significantly associated with a decrease in air pollution as hypothesized. The inverse association between walkability and park proximity may be reflecting more green space in sub-urban environments that are also associated with less walkability. An increase in NDVI was associated with a decrease in the distance to a park. No association was observed between green space and social support. Increasing NDVI was also associated with a decrease in depression but showed no association with stress. Overall, associations between term birth weight and residential green spaces tended to increase with each mediating pathway that was considered, except for physical activity opportunities, which slightly attenuated associations. The fully adjusted model, including model 3 plus all pathway variables showed an increase in birth weight of $29.3 \mathrm{~g}$ $(95 \%$ CI $-1.2,59.8)$ with a 0.1 increase in NDVI within $500 \mathrm{~m}$.

\section{Sensitivity analyses}

We evaluated the sensitivity of our main model results to the inclusion of noise estimates (for Vancouver and Toronto), neighborhood random effects, and season. Noise models were available for Vancouver and Toronto. Our main model for these two cities combined showed that a 0.1 unit increase in NDVI is associated with a $41.2 \mathrm{~g}(95 \% \mathrm{CI} 7.8,74.6)$ increase in term birth weight. This results reflects the larger associations we observed in our Vancouver and Toronto stratified models (Fig. 2). When all mediating variables (from Table 3 ) are added to the model for Vancouver and Toronto we observed a $60.2 \mathrm{~g}(95 \%$ CI 18.6, 101.8) increased for a 0.1 increase in NDVI. Further inclusion of noise estimates for these cities did not substantially attenuate the NDVI and term birth weight associations in our overall models. Including a random effect for census tracts, to further control for potential unmeasured contextual factors, did not change model results. We also explored including a variable for season in place of the birth month to determine if this would have an impact on birth weight, given the differences in season between the four cities in the CHILD study. In the overall model, we did not see any change in the associations once season was added. When including season in the models stratified by city the association was further attenuated in Winnipeg, with no changes in the other three cities.

\section{Discussion}

We investigated the association and potential pathways linking proximity to green space during pregnancy (assessed using NDVI), and term birth weight for 2510 births in four Canadian cities. We observed positive associations between increasing exposure to green space and increased term birth weight in models adjusted for potential individual and neighborhood confounding factors. Overall associations for the four cities were not statistically significant, but stronger statistically significant associations were observed for mothers living in high-density locations and the cities of Vancouver and Toronto. We did not observe substantial reductions in the green space and birth weight association with the addition of hypothesized pathway variables, which was consistent across all cities.

Our overall findings of a potential association between residential green space and term birth weight (ranging from 0.4 to 22.1 grams with a 0.1 unit increase in NDVI) generally corresponds to the existing literature. In a separate study in Vancouver Canada, a 0.1 increase in NDVI (within $100 \mathrm{~m}$ of mothers homes) was associated with a $20.4 \mathrm{~g}$ increase in term birth weight [6]. If we restricted our analyses to Vancouver and to NDVI within $100 \mathrm{~m}$ we observed a $18.5 \mathrm{~g}(95 \% \mathrm{CI}-29.5,65.9)$ increase per 0.1 increase in NDVI. While a number of other studies have observed increases in term birth weight with residential NDVI [4, 45], other studies have not [46]. For example, in Texas, there were strong positive impacts from greenness on birth weight in unadjusted models, but most of the relationship disappeared when including individual characteristics such as race and ethnicity [46]. In our study, we were able to control for several individual-level factors not available in registry based studies, and adjustments for individual socio-demographic factors tended to increase, rather than attenuate, our observed associations. This suggests that the associations we observed between green space and term birth weight are not due to residual confounding. 


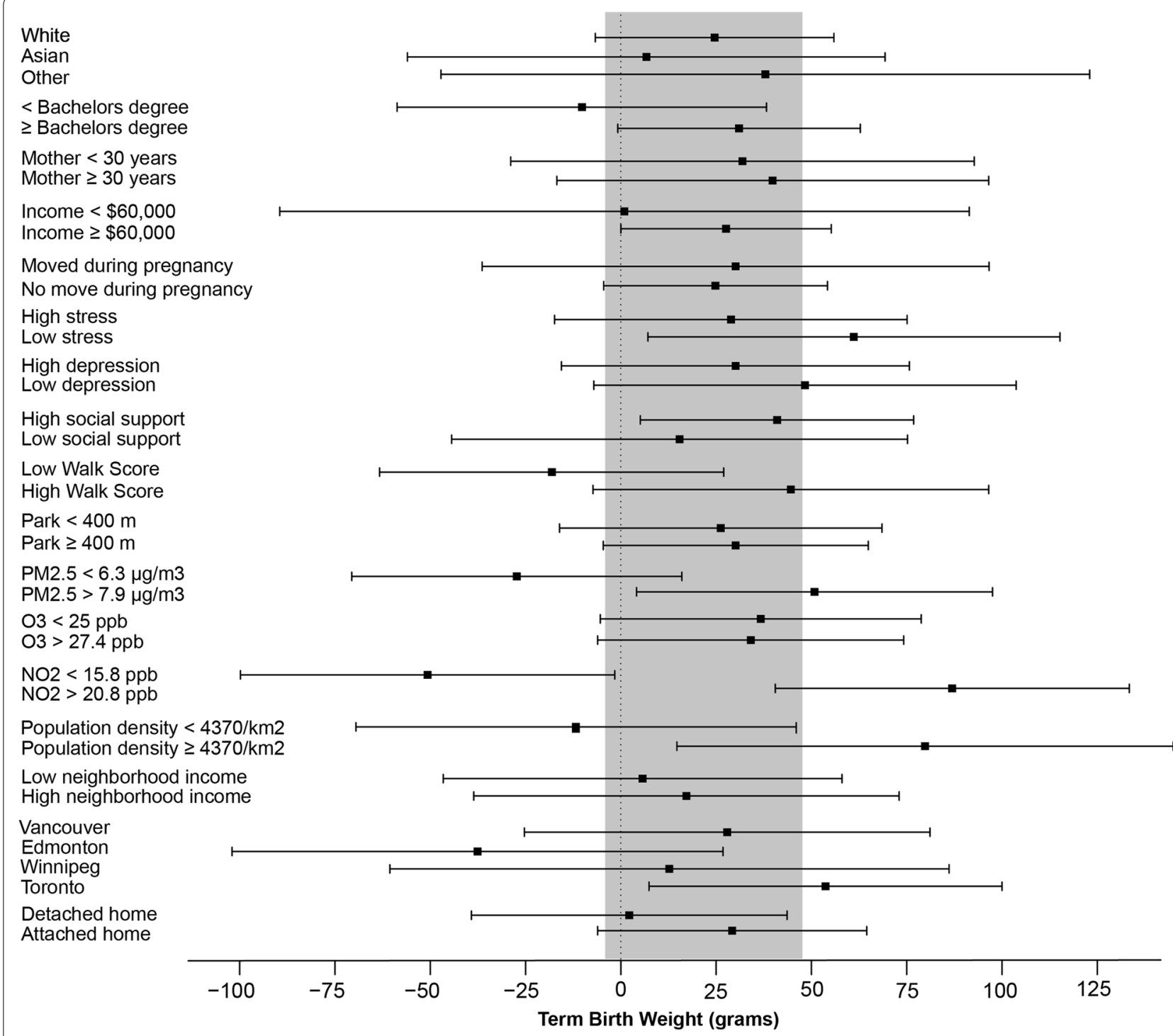

Fig. 2 Stratified models of change in term birth weight (grams) for a 0.1 unit increase in average NDVI within $500 \mathrm{~m}$ of mothers' homes during pregnancy. Shaded region represents $95 \%$ confidence intervals for overall model results

We observed mixed associations across the four Canadian cities included in the CHILD cohort. For Vancouver and Toronto, which are the third and first largest cities in Canada, respectively [47], we observed strong positive associations while there was a negative association in Edmonton and no association in Winnipeg. These differences may be due to a density related effect, as we observed stronger associations between green space and term birthweight for mothers living in locations with a population density $>4370$ individuals per square $\mathrm{km}$ and for individuals with high $\mathrm{NO}_{2}$ exposure and walkability ${ }^{\circledR}$ scores (typically located in high density areas). We note that in our stratified analyses, we found stronger association for mothers living in apartments/condos compared to those residing in single family detached house, another potential surrogate for density/urbanicity. The types of vegetation and associated biological exposures, the accessibility of green space, proximity to blue space and climate also varies considerably across these four cities, which could affect the nature of the association between green space and term birth weights. Toronto and Vancouver are more moderate climates $\left(-2{ }^{\circ} \mathrm{C}\right.$ average minimum winter temp vs. $-16{ }^{\circ} \mathrm{C}$ in Edmonton and Winnipeg); however, our sensitivity analysis including season of birth did not change our findings. The results of our city specific analysis suggest that much more research is needed to understand if green space benefits are restricted to high-density city locations, where green 
Table 3 Associations between a 0.1 IQR increase in residential NDVI in $500 \mathrm{~m}$ and individual pathway variables and combined models of NDVI and term birth weight associations adjusted for pathway variables

\begin{tabular}{|c|c|c|}
\hline & $\begin{array}{l}\text { Association between NDVI }(500 \mathrm{~m}) \\
\text { and each pathway variable* }\end{array}$ & $\begin{array}{l}\text { Association between NDVI }(500 \mathrm{~m}) \text { and term } \\
\text { birth weight adjusting for pathway variable }\end{array}$ \\
\hline Model 3 (fully adjusted model) & & $21.5(-4.6,47.7)$ \\
\hline \multicolumn{3}{|l|}{ Air pollution } \\
\hline $\mathrm{NO}_{2}(\mathrm{ppb})$ & $-2.0(-2.3,-1.8)$ & $25.0(-2.5,52.5)$ \\
\hline $\mathrm{PM}_{2.5}\left(\mu \mathrm{g} / \mathrm{m}^{3}\right)$ & $-0.2(-0.2,-0.1)$ & $21.7(-4.5,47.8)$ \\
\hline $\mathrm{O}_{3}\left(\mu \mathrm{g} / \mathrm{m}^{3}\right)$ & $-0.1(-0.2,-0.004)$ & $24.4(-2.3,51.2)$ \\
\hline Model $3+$ all air pollution variables & & $27.3(-1.0,55.7)$ \\
\hline \multicolumn{3}{|l|}{ Physical activity opportunities } \\
\hline Walk score & $-7.7(-9.1,-6.3)$ & $19.0(-8.6,46.6)$ \\
\hline Park proximity (meters) & $-10.1(-212.1,191.9)$ & $16.1(-10.5,42.7)$ \\
\hline Water proximity (meters) & $81.7(-123.1,286.6)$ & $21.8(-4.4,48.0)$ \\
\hline Model $3+$ all physical activity variables & & $18.9(-8.8,46.5)$ \\
\hline \multicolumn{3}{|l|}{ Psychosocial influences } \\
\hline Social support & $-0.1(-0.2,0.4)$ & $22.1(-5.1,49.4)$ \\
\hline Model $3+$ social support & & $22.1(-5.1,49.4)$ \\
\hline \multicolumn{3}{|l|}{ Psychological influences } \\
\hline Depression & $-0.4(-0.8,0.1)$ & $22.6(-4.6,49.8)$ \\
\hline Stress & $0.0(-0.4,0.4)$ & $22.2(-5.1,49.4)$ \\
\hline Model 3 + All psychological influences variables & & $23.1(-4.3,50.5)$ \\
\hline Model $3+$ all pathway variables & & $29.3(-1.2,59.8)$ \\
\hline
\end{tabular}

* Associations are for a 0.1 IQR increase in residential NDVI in 500 meters

** Adjusted models include: gestational age, baby's sex, year and month of birth, mother's age, mothers smoking during pregnancy, mother/father education, mother/father race/ethnicity, household income, indoor air quality index, city, neighborhood household income, \% without high school education, unemployment, \% minority and population density at $1 \mathrm{~km}$

space is limited, and how green space affects may vary across diverse climate conditions.

Understanding how green space may influence birth outcomes is needed and our study is the first to examine a comprehensive number of hypothesized pathways. Opposite to our a priori hypotheses, we found that the pathways examined (air pollution/noise, physical activity opportunities, social capital and stress/depression) did not explain the observed associations between green space and birth weight in these Canadian cities. This suggests that our variables may not be properly measuring the specific hypothesized pathways of interest; that other pathways not included in our models are present; or that the relationship between residential green space and birth outcomes is due to residual or unmeasured confounding factors.

In our analysis, controlling for $\mathrm{NO}_{2}, \mathrm{PM}_{2.5}$ and $\mathrm{O}_{3}$ did not change the association between NDVI and birth weight. There are mixed findings in the literature as to whether air pollution mediates green space effects and little is known specifically for adverse birth outcomes [2, 5 , 32, 45]. For example, in a Spanish cohort, adjusting for $\mathrm{NO}_{2}$ reduced the magnitude of association between green space and birth weight from 22.3 to $17.1 \mathrm{~g}$ [5]. However, a similar study in Munich observed a slight increase in birth weight after adjusting for $\mathrm{NO}_{2}$ and $\mathrm{PM}_{2.5}$, from 12.2 to 16.2 and $14.8 \mathrm{~g}$ respectively [45]. A previous study in Vancouver, Canada examined the influences of air pollution and found little effect on the green space-birth weight associations [32]. The combined weight of these findings suggests that buffering of harmful environmental pollutants does not account for the observed associations between NDVI and birth weight; however, the relationships between home air pollution exposure and surrounding green space (and the relative locations of the green buffers) may require more detailed data to tease apart.

Examining the physical activity pathway, we found that Walkscore ${ }^{\circledR}$ attenuated the association slightly (though not significantly), while proximity to parks and water had little effect. The correlation between NDVI and Walkscore $^{\circledR}$ was -0.31 . A growing body of research has demonstrated that physical activity during pregnancy can reduce the risk of having a low birth weight baby [16-19]. Unfortunately, we did not have information on mother's physical activity levels during pregnancy and we only examined built environment features that may promote physical activity (and be related to green space). In the current analysis, the individual models stratified 
for walkability and distance to the nearest park has little effect on the green space association. In the future, a direct measure of physical activity (e.g., accelerometry) would be more appropriate for examining this pathway.

We observed a negative association between NDVI and mothers who reported depression but not stress. These findings are consistent with a study examining the association between NDVI and stress and depression in twins that found that greater access to green space was associated with less depression but found less evidence for effects on stress [48]. Maternal depression has also been linked to low birth weight $[29,49]$. Consistent with this, the stratified analysis showed that green space had a larger positive effect on birth weight when the mother was not depressed, compared to depressed. A study in Bradford, England, also observed an association between green space and depressive symptoms in pregnant women but this was only significant for women with lower education or who were physically active [10]. The study also determined that physical activity was not a mediator of the relationship between green space and depressive symptoms [10]. Importantly, we were unable to specifically measure attention restoration, a hypothesized influence of green space [8]. In addition, our measure of stress may not have been sensitive to the hypothesized stress reduction potential of green space [8].

Social support has long been considered an important health indicator for women, with research showing that low social support has a significant direct effect on birth weight $[27,28]$. In our study we observed that NDVI was weakly inversely correlated with social support. However, other studies have found that proximity to green space is associated with increased social support [26], by providing a meeting place for people to develop and maintain social interactions [25]. While our analysis did not show any changes in birth weight when adjusting for social support, in stratified models we observed a greater increase in birth weight for low compared to high social support (e.g., an increase of $41.0 \mathrm{~g}(95 \%$ CI .1, 76.8) for a 0.1 unit increase in NDVI within $500 \mathrm{~m}$ for mothers with reported low social support. This interaction is consistent with the literature demonstrating that health benefits from green spaces are unequally distributed among various SES strata. Similarly, Markevych et al. showed better outcomes among the less educated participants, so it could be assumed that a similar gradient of effect from green spaces applies to not only various SES strata but also to psychosocially different groups [45].

\section{Limitations}

While this analysis contains substantial strengths (i.e., large population sample, four distinct cities spanning a large and diverse geographical area, and detailed individual and neighborhood confounding and mediating variables) and contributes important new information on the associations between green space exposure during pregnancy and term birth weight there are limitations to highlight. First, we used a satellite-derived green space measure (NDVI) around mothers' residential addresses to assess "exposure" to green space. However, NDVI represents only the presence of green vegetation and does not capture type, quality or use of green space. Nevertheless, we have improved on previous studies by using $30 \mathrm{~m}$ NDVI estimates and averages for each 9 month pregnancy period, rather than summer maximum or yearly averages. Second, the variables we had available to measure our proposed pathways are not ideal in all cases (e.g., the lack of physical activity measures for mothers) and likely incorporate measurement error (e.g., air pollution and noise models). However, this is the first study that has attempted to evaluate such a diverse range of pathways linking green space to birth outcomes and the lack of attenuation in our green space estimates by these pathways cannot be explained by measurement error alone. Third, the mothers in the CHILD cohort are predominantly white, well educated women that have access to universal health care. This limited the variation in several key socio-demographic characteristics that have been shown previously to modify and potentially mediate green space associations with adverse birth outcomes. However, this also reduced the potential that our results are due to residual confounding by SES, a major question in the green space literature. Finally, even though this is a relatively large prospective birth cohort with very detailed data collection, sample size was limited for stratified and pathway analyses.

\section{Conclusions}

We examined the relationship between green space and term birth weight in a large Canadian birth cohort spanning four cities. We observed positive associations between increasing exposure to green space and increased term birth weight in models adjusted for potential individual and neighborhood confounding factors. Overall associations for the four cities were not statistically significant, but stronger statistically significant associations were observed for mothers living in high-density locations and the cities of Vancouver and Toronto. The hypothesized pathways tested (the reduction of harmful environmental exposures; space for increased utilitarian and recreational physical activity; positive psychosocial influences; and reduced psychological stress and depression) did not explain these positive associations. Our results highlight the need to characterize the interactions between green space, urban density and climate related factors and further evaluate pathways linking residential green space exposures to improved birth outcomes. 


\section{Abbreviations}

AllerGen: Allergy, Genes and Environment; CadnaA: Computer Aided Noise Abatement; CESD-R: Center for Epidemiologic Studies Depression Scale Revised; CHILD: Canadian Healthy Infant Longitudinal Development; CHRONOS: Canadian and Hemispheric Regional Ozone and NOx System; CIHR: Canadian Institutes of Health Research; ISEL-12: Interpersonal Support Evaluation List-12; LUR: Land use regression; NCE: Network of Centres of Excellence; NDVI: Normalized difference vegetation index; $\mathrm{NO}_{2}$ : Nitrogen dioxide; $\mathrm{O}_{3}$ : Ozone; PM2.5: Fine particulate matter; PSS: Perceived Stress Scale; SES: Socioeconomic status.

\section{Authors' contributions}

$\mathrm{PH}$ conceptualized and designed the study, conducted analysis and wrote the paper; LC and HS conducted statistical analyses and wrote the paper; $\mathrm{AL}$ conducted exposure measures for green space; AC, JB, AK, and TT contributed and/or created exposure or mediation variables; AB, PS, AK, ST, MBA, TM directed data collection at CHILD sites; and MS directed the CHILD study. All authors contributed to scientific discussions of methodology, statistical analyses and interpretation. All authors edited the final paper.

\section{Author details}

${ }^{1}$ Oregon State University, Corvallis OR, USA. ${ }^{2}$ University of British Columbia, Vancouver, BC, Canada. ${ }^{3}$ Indiana University, Bloomington, IN, USA. ${ }^{4}$ University of Toronto, Toronto, ON, Canada. ${ }^{5}$ Hospital for Sick Children, Toronto, ON, Canada. ${ }^{6}$ University of Alberta, Edmonton, AB, Canada. ${ }^{7}$ University of Manitoba, Winnipeg, MB, Canada. ${ }^{8}$ Hospital for Sick Children, Toronto, ON, Canada. ${ }^{9}$ Simon Fraser University, Burnaby, BC, Canada. ${ }^{10}$ McMaster University, Hamilton, ON, Canada. ${ }^{11}$ BC Children's Hospital, Vancouver, BC, Canada. ${ }^{12} \mathrm{Col}-$ lege of Public Health and Human Sciences, Oregon State University, 2520 SW Campus Way, Corvallis, OR 97331, USA.

\section{Acknowledgements}

We are grateful to all the families who took part in this study, and the whole CHILD team, which includes interviewers, nurses, computer and laboratory technicians, clerical workers, research scientists, volunteers, managers, and receptionists. The Canadian Institutes of Health Research (CIHR) and the Allergy, Genes and Environment (AllerGen) Network of Centres of Excellence (NCE) provided core funding for CHILD. Additional support has been provided by Health Canada, Environment Canada, Canada Mortgage and Housing Corporation, the Sick Children's Hospital Foundation, Don \& Debbie Morrison, the Silver Thread Foundation and the Childhood Asthma Foundation.

CHILD Study Investigators: Subbarao P (Director), The Hospital for Sick Children \& University of Toronto; Turvey SE (co-Director), University of British Columbia; Sears MR, (Founding Director), McMaster University; Anand SS, McMaster University; Azad MB, University of Manitoba; Becker AB, University of Manitoba; Befus AD, University of Alberta; Brauer M, University of British Columbia; Brook JR, University of Toronto; Chen E, Northwestern University, Chicago; Cyr MM, McMaster University; Daley D, University of British Columbia; Dell SD, The Hospital for Sick Children \& University of Toronto; Denburg JA, McMaster University; Duan QL, Queen's University; Eiwegger T, The Hospital for Sick Children \& University of Toronto; Grasemann H, The Hospital for Sick Children \& University of Toronto; HayGlass K, University of Manitoba; Hegele RG, The Hospital for Sick Children \& University of Toronto; Holness DL, University of Toronto; Hystad P, Oregon State University; Kobor M, University of British Columbia; Kollmann TR, University of British Columbia; Kozyrskyj AL, University of Alberta; Laprise C, Université du Québec à Chicoutimi; Lou WYW, University of Toronto; Macri J, McMaster University; Mandhane PJ, University of Alberta; Miller G, Northwestern University, Chicago; Moraes TJ, The Hospital for Sick Children \& University of Toronto; Paré P, University of British Columbia; Ramsey C, University of Manitoba; Ratjen F, The Hospital for Sick Children \& University of Toronto; Sandford A, University of British Columbia; Scott JA, University of Toronto; Scott J, University of Toronto; Silverman F, University of Toronto; Simons E, University of Manitoba; Takaro T, Simon Fraser University; Tebbutt SJ, University of British Columbia; To T, The Hospital for Sick Children \& University of Toronto.

\section{Competing interests}

The authors declare that they have no competing interests.
Availability of data and materials

Data from the CHILD study can be requested at: http://childstudy.ca/for-resea rchers/.

\section{Consent for publication}

Not applicable. There is no individual level data in our publication.

\section{Ethics approval and consent to participate}

The Human Research Ethics Boards at McMaster University, and Oregon State University approved this study.

\section{Funding}

Canadian Institutes of Health Research (CIHR), Allergy, Genes and Environment Network of Centers of Excellence (AllerGen NCE, Inc.)

\section{Publisher's Note}

Springer Nature remains neutral with regard to jurisdictional claims in published maps and institutional affiliations.

\section{Received: 18 August 2018 Accepted: 22 November 2018}

Published online: 04 December 2018

\section{References}

1. Ebisu K, Holford TR, Bell ML. Association between greenness, urbanicity, and birth weight. Sci Total Environ. 2016;542:750-6.

2. Laurent O, Wu J, Li L, Milesi C. Green spaces and pregnancy outcomes in Southern California. Health Place. 2013;24:190-5.

3. Agay-Shay K, Peled A, Crespo AV, Peretz C, Amitai Y, Linn S, et al. Green spaces and adverse pregnancy outcomes. Occup Environ Med. 2014;71:562-9.

4. Dadvand P, de Nazelle A, Figueras F, Basagaña X, Su J, Amoly E, et al. Green space, health inequality and pregnancy. Environ Int. 2012;40:110-5.

5. Dadvand P, Sunyer J, Basagana X, Ballester F, Lertxundi A, FernandezSomoano A, et al. Surrounding greenness and pregnancy outcomes in four Spanish Birth Cohorts. Environ Health Perspect. 2012;120:1481-7.

6. Hystad P, Davies HW, Frank L, Van Loon J, Gehring U, Tamburic L, et al. Residential greenness and birth outcomes: evaluating the influence of spatially correlated built-environment factors. Vancouver: University of British Columbia; 2015.

7. Banay RF, Bezold CP, James P, Hart JE, Laden F. Residential greenness: current perspectives on its impact on maternal health and pregnancy outcomes. Int J Womens Health. 2017;9:133-44.

8. Markevych I, Schoierer J, Hartig T, Chudnovsky A, Hystad P, Dzhambov $A M$, et al. Exploring pathways linking greenspace to health: theoretical and methodological guidance. Environ Res. 2017;158:301-17.

9. Dadvand P, Bartoll X, Basagaña X, Dalmau-Bueno A, Martinez D, Ambros A, et al. Green spaces and General Health: roles of mental health status, social support, and physical activity. Environ Int. 2016;91:161-7.

10. McEachan RRC, Prady SL, Smith G, Fairley L, Cabieses B, Gidlow C, et al. The association between green space and depressive symptoms in pregnant women: moderating roles of socioeconomic status and physical activity. J Epidemiol Community Health. 2015;70:253-9.

11. Brauer M, Lencar C, Tamburic L, Koehoorn M, Demers P, Karr C. A cohort study of traffic-related air pollution impacts on birth outcomes. Environ Health Perspect. 2008;116:680.

12. Padula AM, Mortimer K, Hubbard A, Lurmann F, Jerrett M, Tager IB. Exposure to traffic-related air pollution during pregnancy and term low birth weight: estimation of causal associations in a semiparametric model. Am J Epidemiol. 2012;176:815-24.

13. Shah PS, Balkhair T. Air pollution and birth outcomes: a systematic review. Environ Int. 2011;37:498-516.

14. Sram RJ, Binkova B, Dejmek J, Bobak M. Ambient air pollution and pregnancy outcomes: a review of the literature. Environ Health Perspect. 2005;113:375-82. 
15. Derkzen ML, van Teeffelen AJA, Verburg PH. REVIEW: quantifying urban ecosystem services based on high-resolution data of urban green space: an assessment for Rotterdam, the Netherlands. J Appl Ecol. 2015;52:1020-32.

16. Leiferman JA, Evenson KR. The effect of regular leisure physical activity on birth outcomes. Matern Child Health J. 2003;7:59-64.

17. Campbell MK, Mottola MF. Recreational exercise and occupational activity during pregnancy and birth weight: a case-control study. Am J Obstet Gynecol. 2001;184:403-8.

18. Hall DC, Kaufmann DA. Effects of aerobic and strength conditioning on pregnancy outcomes. Am J Obstet Gynecol. 1987;157:1199-203.

19. Melzer K, Schutz Y, Boulvain M, Kayser B. Physical activity and pregnancy Sports Medicine. 2010;40:493-507.

20. Wheeler BW, Cooper AR, Page AS, Jago R. Greenspace and children's physical activity: a GPS/GIS analysis of the PEACH project. Prev Med. 2010;51:148-52.

21. Almanza E, Jerrett M, Dunton G, Seto E, Pentz MA. A study of community design, greenness, and physical activity in children using satellite, GPS and accelerometer data. Health Place. 2012;18:46-54.

22. Lachowycz K, Jones AP, Page AS, Wheeler BW, Cooper AR. What can global positioning systems tell us about the contribution of different types of urban greenspace to children's physical activity? Health Place. 2012;18:586-94.

23. Frank LD, Sallis JF, Saelens BE, Leary L, Cain K, Conway TL, et al. The development of a walkability index: application to the Neighborhood Quality of Life Study. Br J Sports Med. 2010;44:924-33.

24. Kaczynski AT, Potwarka LR, Saelens BE. Association of park size, distance, and features with physical activity in neighborhood parks. Am J Public Health. 2008;98:1451-6.

25. Kweon B-S, Sullivan WC, Wiley AR. Green common spaces and the social integration of inner-city older adults. Environ Behavior. 1998:30:832-58.

26. Maas J, Van Dillen SM, Verheij RA, Groenewegen PP. Social contacts as a possible mechanism behind the relation between green space and health. Health Place. 2009;15:586-95.

27. Feldman PJ, Dunkel-Schetter C, Sandman CA, Wadhwa PD. Maternal social support predicts birth weight and fetal growth in human pregnancy. Psychosom Med. 2000;62:715-25.

28. Nkansah-Amankra S, Dhawain A, Hussey JR, Luchok KJ. Maternal social support and neighborhood income inequality as predictors of low birth weight and preterm birth outcome disparities: analysis of South Carolina Pregnancy Risk Assessment and Monitoring System survey, 2000-2003. Matern Child Health J. 2010;14:774-85.

29. Grote NK, Bridge JA, Gavin AR, Melville JL, lyengar S, Katon WJ. A metaanalysis of depression during pregnancy and the risk of preterm birth low birth weight, and intrauterine growth restriction. Arch Gen Psychiatry. 2010;67:1012-24.

30. Moraes TJ, Lefebvre DL, Chooniedass R, Becker AB, Brook JR, Denburg J, et al. The Canadian healthy infant longitudinal development birth cohort study: biological samples and biobanking. Paediatr Perinat Epidemiol. 2015;29:84-92.

31. Takaro TK, Scott JA, Allen RW, Anand SS, Becker AB, Befus AD, et al. The Canadian Healthy Infant Longitudinal Development (CHILD) birth cohort study: assessment of environmental exposures. J Eposure Sci Environ Epidemiol. 2015;25:580.

32. Hystad P, Davies HW, Frank L, Van Loon J, Gehring U, Tamburic L, et al. Residential greenness and birth outcomes: evaluating the influence of spatially correlated built-environment factors. 2014 [cited 2015 Nov 9]. http://ir.library.oregonstate.edu/xmlui/handle/1957/54074.

33. Hystad P, Setton E, Cervantes A, Poplawski K, Deschenes S, Brauer M, et al. Creating national air pollution models for population exposure assessment in Canada. Environ Health Perspect. 2011;119:1123.
34. van Donkelaar A, Martin RV, Brauer M, Hsu NC, Kahn RA, Levy RC, et al. Global estimates of fine particulate matter using a combined geophysical-statistical method with information from satellites, models, and monitors. Environ Sci Technol. 2016;50:3762-72.

35. Pudykiewicz JA, Kallaur A, Smolarkiewicz PK. Semi-Lagrangian modelling of tropospheric ozone. Tellus B. 1997;49:231-48.

36. Gan WQ, McLean K, Brauer M, Chiarello SA, Davies HW. Modeling population exposure to community noise and air pollution in a large metropolitan area. Environ Res. 2012;116:11-6.

37. Zuo F, Li Y, Johnson S, Johnson J, Varughese S, Copes R, et al. Temporal and spatial variability of traffic-related noise in the City of Toronto, Canada. Sci Total Environ. 2014:472:1100-7.

38. Cohen DA, McKenzie TL, Sehgal A, Williamson S, Golinelli D, Lurie N. Contribution of public parks to physical activity. Am J Public Health. 2007;97:509-14.

39. Kaczynski AT, Besenyi GM, Stanis SAW, Koohsari MJ, Oestman KB, Bergstrom R, et al. Are park proximity and park features related to park use and park-based physical activity among adults? Variations by multiple socio-demographic characteristics. Int J Behav Nutr Phys Act. 2014;11:146.

40. Merz EL, Roesch SC, Malcarne VL, Penedo FJ, Llabre MM, Weitzman OB, et al. Validation of interpersonal support evaluation list-12 (ISEL-12) scores among English- and Spanish-speaking Hispanics/Latinos from the HCHS/ SOL Sociocultural Ancillary Study. Psychol Assess. 2014;26:384.

41. Cohen S, KamarckT, Mermelstein R. Perceived stress scale. Measuring stress: A guide for health and social scientists. 1994.

42. Edition F, Association AP. Diagnostic and statistical manual of mental disorders. Washington: American Psychological Association; 1994

43. Takaro TK, Joffres Y, Shu H, Brook J, Becker AB, McLean K, et al. Early life indoor inflammatory exposures and asthma risk at three years of age in the Canadian Healthy Infant Longitudinal Development (CHILD) Birth Cohort. In: B15 HEALTH EFFECTS OF INDOOR/OUTDOOR POLLUTION IN CHILDHOOD. Am Thoracic Soc; 2016. p. A2877-A2877.

44. White MP, Alcock I, Wheeler BW, Depledge MH. Coastal proximity, health and well-being: results from a longitudinal panel survey. Health Place. 2013;23:97-103.

45. Markevych I, Fuertes E, Tiesler CM, Birk M, Bauer C-P, Koletzko S, et al. Surrounding greenness and birth weight: results from the GINIplus and LISAplus birth cohorts in Munich. Health Place. 2014;26:39-46.

46. Cusack L, Larkin A, Carozza S, Hystad P. Associations between residential greenness and birth outcomes across Texas. Environ Res. 2017;152:88-95.

47. Statistics Canada. Population of census metropolitan areas [Internet]. [cited 2017 Sep 29]. http://www.statcan.gc.ca/tables-tableaux/sum-som/ 101/cst01/demo05a-eng.htm.

48. Cohen-Cline H, Turkheimer E, Duncan GE. Access to green space, physical activity and mental health: a twin study. J Epidemiol Community Health. 2015;69:523.

49. Field T, Diego M, Hernandez-Reif M, Figueiredo B, Deeds O, Ascencio A, et al. Comorbid depression and anxiety effects on pregnancy and neonatal outcome. Infant Behav Dev. 2010;33:23-9.

Ready to submit your research? Choose BMC and benefit from:

- fast, convenient online submission

- thorough peer review by experienced researchers in your field

- rapid publication on acceptance

- support for research data, including large and complex data types

- gold Open Access which fosters wider collaboration and increased citations

- maximum visibility for your research: over 100M website views per year

At BMC, research is always in progress.

Learn more biomedcentral.com/submissions 